\section{Modelo teórico relacionando as potências elétrica e química em célula fotossensibilizada com corante}

\section{Theoretical model that relates both electrical and chemical power in photosensitizeddye-cells}

\section{Francisco Marcone Lima $^{1}$,Karine Pereira Bezerra ${ }^{2}$ Maria Katiane Diógenes Marques ${ }^{3}$,Paulo Herbert França Maia Júnior ${ }^{4}$ Francisco Nivaldo Aguiar Freire ${ }^{5}$, Ana Fabíola Leite Almeida ${ }^{6}$}

\author{
${ }^{1}$ Programa de Pós-Graduação em Engenharia e Ciência de Materiais - UFC CEP: 60455-900, Fortaleza, CE \\ e-mail: marco- \\ neufc@gmail.com \\ mento de Engenharia Química - UFC CEP: 60455-900, Fortaleza, CE \\ e-mail: karinepereira.bezerra@hotmail.com; katia- \\ nedm@hotmail.com \\ 4,5,6 Programa de Mestrado em Engenharia Mecânica - UFC CEP: 60455-900, Fortaleza, CE \\ e-mail: phfmj@yahoo.com.br; nivaldo@ufc.br; anfaleal@yahoo.com.br
}

\section{RESUMO}

Este trabalho apresenta um modelo teórico que relaciona a potência elétrica com a potência química numa célula fotossensibilizada com corante. O mesmo é baseado na junção dos conceitos presentes nos modelos de potencial químico e de potência química. Assim, a partir destas duas considerações é possível a realização de testes sob diversas condições físicas e ambientais, durante o processo de conversão de energia solar. Consequentemente, o modelo teórico proposto permite relacionar a potência química aos parâmetros solares: ângulo sólido, temperatura da fonte de radiação, comprimento de onda e temperatura da célula fotossensibilizada com corante. A geração do fluxo de elétrons dentro da célula é promovida pela absorção da energia solar incidente sobre o corante. Por isso, a principal condição consubstanciada neste trabalho baseia-se que a superfície de absorção da energia incidente seja o corante.

Palavras-chave: Energia Solar, Célula fotossensibilizada com corante, Potência Elétrica, Potência Química.

\section{ABSTRACT}

This paper presents a theoretical model relating the electrical power to the chemical power in a photosensitized dye-cell. The same is based on the junction of present concepts of chemical potential models and chemical power. Thus, from these two considerations is possible to perform tests under various physical and environmental conditions during the solar conversion process. Consequently, the proposed theoretical model allows relating the power to solar chemical parameters: solid angle, temperature of the radiation source, wavelength and temperature of the photosensitized dye-cell. The electrons flow generation within the cell is promoted by absorption of solar energy incident on the dye. Therefore, the main condition embodied in this work is based on the incident energy absorption surface is the dye.

Keywords: Solar Energy, Dye-cells, Chemistry Power, Electric Power.

\section{INTRODUÇÃO}

Modelos são representações simplificadas dos sistemas físicos, ou seja, consistem na representação de sistemas ou processos reais em forma de equações. A convolução, isto é, a representação de sistemas físicos em forma de equações, baseia-se em princípios físicos e, também, em princípios químicos como também em relações obtidas experimentalmente; quando possível. Além disso, o sistema físico real deve ser abstraído de forma a extrair somente os aspectos relevantes para as características a serem analisadas. 
A caracterização elétrica de células fotovoltaicas é feita com o auxílio de modelos baseados em circuito elétrico [1,2]. A célula fotovoltaica fotossensibilizada é composta por corante fotossensível e eletrólito redox entre semicondutores (Figura 1). O eletrólito redox tem a função de regenerar o corante fotossensível e assim tornar o processo de geração de fotocorrente reversível [్-ㅁ]. Basicamente, a fotocorrente elétrica é gerada devido à absorção de energia (luz), proveniente do sol ou de uma fonte artificial, pelo corante (S), tal processo é ilustrado na Figura 2.

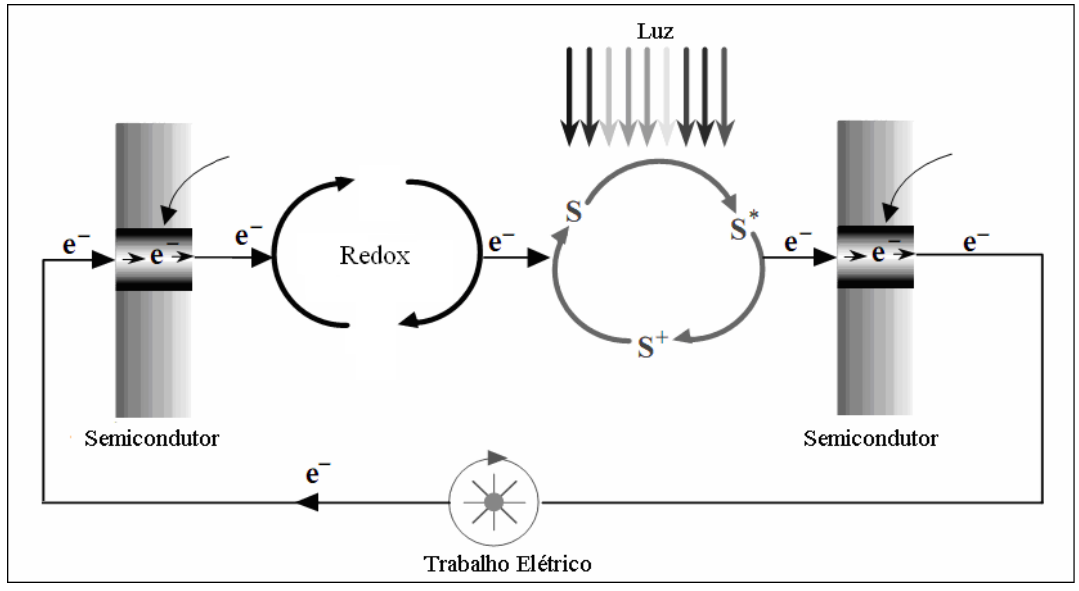

Figura 1: Células fotossensibilizadas com corante: Esquema genérico.

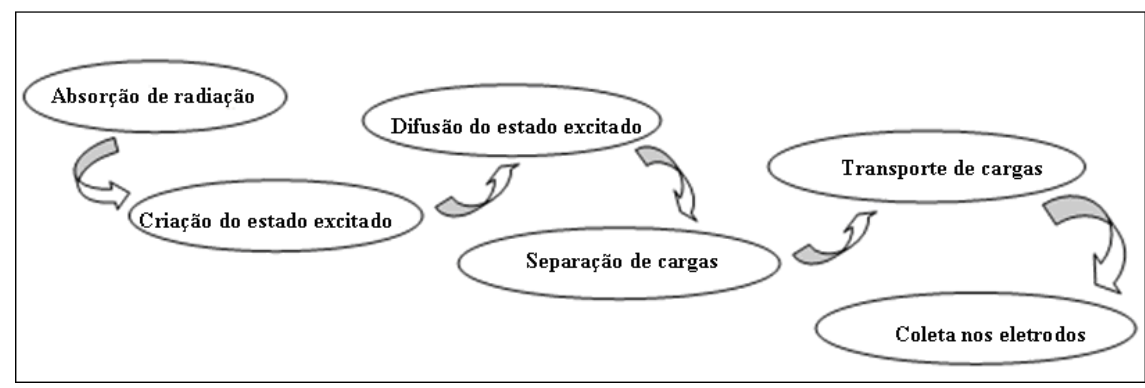

Figura 2: Processos envolvidos na geração de corrente elétrica em células fotossensibilizadas com corante.

Este trabalho tem como proposta apresentar um modelo teórico para relacionar a potência elétrica com a potência química em células fotossensibilizadas com corante. Além disso, indicar alguns fatores que limitam a conversão de energia solar em células fotossensibilizadas com corante. O modelo teórico baseia-se na camada de corante e nos princípios termodinâmicos aplicados a reações fotoquímicas. As condições principais adotadas no modelo são: a camada de corante (única superfície fotossensível), o potencial químico é gerado durante a reação fotoquímica reversível e sem formação de subprodutos. Além disso, assume-se que a célula é exposta a radiações monocromática e policromática e a eficiência ( $\eta$ ) é função do comprimento onda $(\lambda)$, ângulo sólido $(\Omega)$, temperatura da fonte de radiação $\left(T_{R}\right)$.

\section{MATERIAIS E MÉTODOS}

\subsection{Modelo Teórico}

O modelo teórico para relacionar a potência elétrica com a potência química em célula fotossensibilizada ilustrado neste trabalho faz a concatenação das teorias envolvendo dois outros modelos teóricos. O primeiro modelo é destinado a estimar a eficiência teórica de conversão da energia solar em uma superfície fotossensível. O segundo modelo relaciona as potências química e elétrica em uma célula combustível. Além disso, ambos os modelos baseam-se na variação de potencial químico $(\Delta \mu)$.

\subsection{Condição de potencial químico}


A radiação solar é uma forma de energia recebida pela Terra. O sol emite radiação com comprimentos de onda que vão desde o ultravioleta, passando pelo visível, até o infravermelho. Quando a radiação proveniente de fonte natural (sol) ou artificial incide sobre um objeto três fenômenos diferentes podem ocorrer: absorção, reflexão e transmissão. A transmissão está relacionada com a transparência do objeto, enquanto que os fenômenos de absorção e reflexão estão relacionados à percepção da cor do objeto. Isso decorre da capacidade da superfície de absorver, transmitir ou refletir em comprimentos de onda determinados que é uma característica específica a cada material.

A radiação solar é responsável por diversos processos de transformação energética que ocorrem na Terra, desde fenômenos atmosféricos e até mesmo na formação dos combustíveis fósseis. Também, o sol emite radiação em vários comprimentos de onda e às vezes é mais conveniente analisar a radiação eletromagnética a partir da perspectiva da mecânica quântica, na qual a radiação é composta de pacotes de energia (fótons). Resumidamente, a energia dos fótons é uma função da velocidade da luz (c), do comprimento de onda $(\lambda)$ e da constante universal chamada de constante de Planck $(h)$.

A propriedade importante das células de Grätzel é a capacidade de absorver fótons, energia na forma de radiação incidente, e converter os fótons a partir camada de corante fotossensível (S), por meio de reações fotoquímicas, em corrente elétrica [6]. A fotoquímica quando associada aos princípios da termodinâmica fornece contribuição para o entendimento dos fatores que determinam as limitações no processo de conversão da radiação em reações fotoquímicas [7].

Em resumo, nas reações químicas o propósito é converter os reagentes químicos em energia e nas reações fotoquímicas é converter a radiação eletromagnética em potencial químico. No entanto, os princípios da termodinâmica impõem limitações para o processo de conversão da radiação incidente (luz) em potencial químico. A perda de energia durante o processo fotoquímico tem diversas origens [7], dentre elas:

- Entropia da radiação incidente;

• Condição de não equilíbrio no sistema;

- Aumento da entropia devido ao espalhamento ou absorção da radiação;

- Baixa eficiência de conversão para radiação policromática comparada com a monocromática.

As principais variáveis que influenciam a taxa em uma reação química são a temperatura, a pressão e a composição. Assim, no sistema envolvendo reações químicas a energia de Gibbs $(G)$ associada ao sistema é função da temperatura (T), pressão $(P)$, composição $(X)$, ou seja, $G=\mathrm{f}\left(T, P, X_{1}, \ldots, X_{n}, X_{n+1}, \ldots\right)$. A energia de Gibbs de um sistema diminui durante um processo a $T$ e $P$ constantes, isto é, durante um processo isotérmico e adiabático, onde a condição de equilíbrio é alcançada quando $G$ atinge valor mínimo. Assim, se um sistema não está em equilíbrio, qualquer reação a $T$ e $P$ constantes leva a uma diminuição na energia de Gibbs do sistema. Ao considerar que existe uma única variável denominada $m$ que caracteriza o processo de reação, consequentemente a energia de Gibbs do sistema, com os demais parâmetros constantes, é determinada pela variável $m$.

Ao considerar que a composição denominada $X_{n}$ é a variável $m$, o valor da energia de Gibbs em processos a $T$ e $P$ constantes é função apenas da composição. Por conseguinte, uma vez que o potencial químico ( $\mu$ ) é por definição a energia de Gibbs em função da composição, então o conhecimento do valor do $\mu$ no nésimo componente do sistema significa conhecer também o valor de $G$. Segundo a literatura, a variação da energia de Gibbs $(\Delta G)$ pode ser interpretada como a energia disponível para realizar trabalho e a variação do potencial químico $(\Delta \mu)$ permite estimar a energia disponível para realizar trabalho.

Para uma reação fotoquímica, ao considerar que o sistema é composto por numa superfície genérica, então para uma molécula $A$ do corante há um potencial químico $\left(\mu_{A}\right)$ associado. Ao absorver fótons a molécula $A$ passa para o estado excitado $\left(A^{*}\right)$, com potencial químico $\left(\mu_{A^{*}}\right)$ [7], ou seja;

$$
\underset{\mu_{A}}{A}+\underset{\mu_{v}}{\stackrel{k_{d}}{\leftrightarrow}} \stackrel{\stackrel{k_{i}}{\leftrightarrow}}{\mu^{*}} A^{*}
$$

Sendo $\mu_{v}$ a fração molar do quanta de radiação absorvida que equivale ao potencial químico da radiação, em analogia ao potencial químico; $h$ é a constante de Planck ; $v$ é a frequência da luz; $k_{d}$ e $k_{i}$ são respectivamente as constante das velocidades direta e inversa da reação.

Em substâncias fotossensíveis, devido à absorção de radiação, há a geração de uma reação química e, 
por conseguinte a formação de um potencial químico associado ao produto. Para uma reação fotoquímica com velocidade de reação $J$, a energia extraída da radiação ou a potência de conversão da reação está relacionada à geração de produto $A^{*}$, no qual há geração de potencial químico associado $\left(\mu_{A^{*}}\right)$ que pode ser representado pela Eq. (2). Em condições ideais, a variação do potencial químico $(\Delta \mu)$ no processo de fotoquímico espontâneo pode ser estimada baseada na isotérmica de Van’t Hoff [7], representado pela Eq. (3.1):

$$
\begin{aligned}
& E=J \cdot \mu_{A^{*}}=J \cdot\left(\mu_{A}+\mu_{V}+\Delta \mu\right) \\
& \Delta \mu=\mu_{A^{*}}-\mu_{A}-\mu_{v}=R \cdot T \cdot \ln (1-\varphi)
\end{aligned}
$$

No qual $R$ é a constante universal dos gases, $T$ a temperatura em Kelvin do sistema reacional e $\varphi$ é o fator adimensional que relaciona a velocidade global da reação $(J)$ com a velocidade da reação direta $\left(j_{d}\right)$ :

$$
\varphi=\frac{J}{j_{d}}
$$

A variação de potencial químico pode ser interpretada como a exportação de energia armazenada pela superfície fotossensível extraída da fonte radiante. O potencial químico para a radiação $\left(\mu_{v}\right)$ em processos de absorção com reação fotoquímica associada, pode ser estimado em função do fator adimensional $\varphi$ [7]. Assim, $\mu_{v}$ pode ser estimado ao considerar o potencial químico do elemento $A$ como potencial de referência e com valor zero $\left(\mu_{A}=0\right)$ e, em seguida, aplicar a derivada, Eq. (2), isto é, à máxima potência de conversão. Por outro lado, a Eq. (4) também pode ser usada para estimar o potencial químico para a radiação $\left(\mu_{v}\right)$, ou seja;

$$
\frac{\mu_{V}}{R T}=\frac{\varphi}{1-\varphi}-\ln (1-\varphi)
$$

\subsection{Condição de radiação monocromática}

A máquina de Carnot aplicada à radiação limita a máxima eficiência de conversão da energia solar. A quantidade máxima de energia solar por mol $\left(Q_{R}\right)$ que pode ser utilizada na produção de trabalho na temperatura ambiente obedece a eficiência de Carnot [7]. Ao se considerar que o material está à temperatura ambiente $T_{A}$ e a fonte de radiação está à $T_{R}$, o potencial químico máximo da radiação $\left(\mu_{v}\right)$ é dado por:

$$
\mu_{v}=\frac{Q_{R} \cdot\left(T_{R}-T_{A}\right)}{T_{R}}
$$

Os estudos da temperatura do corpo negro através das leis de Planck, Stefan-Boltzmann e Wien conduzem a valores diferentes para a temperatura da fonte de radiação, pois dependem dos procedimentos utilizados. A diferença entre os valores estimados demonstra que o sol não emite como um corpo negro e, por isso, não é possível assumir um único valor para a temperatura $\left(T_{R}\right)$. Ao considerar a fonte de radiação sendo o sol, cuja radiação tem vários comprimentos de onda, estudos mostram que existem forte variação da temperatura na própria atmosfera solar. Contudo, para a condição de radiação monocromática com comprimento de onda específico $\lambda$, a energia recebida por mol $\left(Q_{R}\right)$ pode ser expressa na forma:

$$
Q_{R}=\frac{N . h . c}{\lambda}=N . h . v
$$

Sendo $N$ é o número de Avogadro, $h$ a constante de Planck, $c$ a velocidade da luz e $v$ a frequência.

De forma geral, há dois teoremas importantes relacionados ao rendimento termodinâmico do ciclo de Carnot. Primeiro teorema relata que não é possível à construção de um motor real que trabalhe entre dois reservatórios térmicos e que tal motor seja mais eficiente que um motor reversível (ideal) operando entre os mesmos dois reservatórios. O segundo teorema afirma que todos os motores que operam pelo ciclo de Carnot e entre dois reservatórios de temperatura constante tem o mesmo rendimento térmico. Pelos princípios da termodinâmica a eficiência máxima de conversão é obtida somente pela maquina térmica de Carnot [8] . A eficiência máxima de conversão da energia solar $\left(\eta_{r}\right)$ pode ser representada pela fórmula de Carnot aplicada à radiação [7], representado pela Eq. (7). 
LIMA, F.M., BEZERRA, K.P., MARQUES, M.K.D, MAIA JÚNIOR, P.H.F, FREIRE,F.N.A.,ALMEIDA,A.F.L. revista Matéria, v.20, n.2, pp. $344-352,2015$.

$$
\eta_{r}=\frac{\mu_{v}}{Q_{R}}=\frac{T_{R}-T_{A}}{T_{R}}
$$

Todo corpo quente irradia em comprimentos de onda dentro do espectro eletromagnético. As leis para a irradiação são apresentadas na forma mais simples para o corpo negro à temperatura $T$. A fórmula de Planck é a lei central para um radiador térmico e pode ser representada de várias formas. Assim, a temperatura do corpo negro $\left(T_{R}\right)$, não considerando o espalhamento ou absorção da luz, é dada pela Eq. (8a) que é uma variação da equação de Planck. Ao considerar o espalhamento da luz, neste caso, tem-se a chamada temperatura efetiva $\left(T_{R s}\right)$, ver Eq. (8b), que torna as Eqs. (5) e (7) mais representativas, isto é, os valores fornecidos próximos de valores experimentais. Por outro lado, assumindo a massa de ar AM 1,5 pode-se considerar a temperatura do corpo negro sem espalhamento da luz $\left(T_{R}\right)$ de 5200K [7].

$$
\begin{gathered}
T_{R}=\frac{h \cdot c}{k_{B} \cdot \lambda} \cdot\left(\frac{1}{\ln \left(1+\frac{2 \cdot \pi \cdot h \cdot c^{2} \cdot \Omega}{\lambda^{5} \cdot I_{\lambda}}\right)}\right) \\
T_{R s}=\frac{h \cdot c}{k_{B} \cdot \lambda} \cdot\left(\frac{1}{\ln \left(1+\frac{8 \cdot \pi \cdot h \cdot c^{2}}{\lambda^{5} \cdot I \lambda}\right)}\right)
\end{gathered}
$$

Nas Equações 8a e 8b, $I_{\lambda}$ refere-se à potência irradiada por unidade de área de um corpo negro na temperatura $T$ por unidade de comprimento de onda ou irradiação espectral, cuja unidade é W.m ${ }^{-2} \cdot \mathrm{nm}^{-1} ; \Omega$ é o ângulo sólido e $k_{B}$ é a constante de Boltzmann.

Em condição ideal, à máxima energia extraída ou eficiência de conversão da luz $\left(\eta_{g}\right)$ com uso de radiação monocromática com reação fotoquímica associada pode ser expressa em função da variação do potencial químico e da energia da radiação incidente [7]. A eficiência de conversão da luz equivale à eficiência da reação fotoquímica. Portanto, com o auxílio das Eqs. (3.2) a (8a), a Equação (3.1) pode ser reescrita nas formas das Eqs. (9a) e (9b) que permite estimar a eficiência de conversão da radiação monocromática de comprimento $\lambda$ em processos fotoquímicos. Neste caso, a eficiência é uma função dos potenciais químicos associado aos estados fundamental $\left(\mu_{A}\right)$ e excitado $\left(\mu_{A^{*}}\right)$ da molécula de corante.

$$
\begin{aligned}
& \frac{\left(\mu_{A^{*}}-\mu_{A}\right)}{N . h . c / \lambda}=1-\frac{T_{A}}{T_{R}}-\frac{R \cdot T_{A} \cdot \lambda}{N . h . c} \ln (4 \pi / \Omega)+\frac{R \cdot T \cdot \lambda}{N \cdot h \cdot c} \ln (1-\varphi) \\
& \eta_{g}=\frac{\left(\mu_{A^{*}}-\mu_{A}\right)}{N . h . c / \lambda}
\end{aligned}
$$

Os últimos três termos do lado direito na Eq. (9a) representam as perdas devido à entropia da radiação (luz), o aumento da entropia devido à absorção ou o espalhamento da luz e as perdas causadas pelas condições de não equilíbrio do sistema reacional, respectivamente. No processo de conversão da energia solar em energia elétrica deve-se considerar a influência da fração da energia absorvida da radiação policromática $(\theta)$ [7]. A eficiência máxima em processos fotoquímicos, considerando fonte de luz policromática é dada por:

$$
\eta=\eta_{g} \cdot \theta
$$

\subsection{Potência elétrica}

Uma célula combustível é similar em alguns aspectos a uma célula eletrolítica ou bateria. A célula é o dispositivo pelo qual o combustível é oxidado eletroquimicamente para produzir potência elétrica. As células combustíveis têm características de bateria por possuir dois eletrodos separados por um eletrólito, mas nelas não há armazenamento do eletrólito como ocorre nas baterias. Os reagentes são alimentados continuamente e os produtos da reação são também retirados continuamente.

Em uma célula combustível trabalhando reversivelmente a potência química $\left(P_{q}\right)$ é igual à potência elétrica $(P)[\underline{9}$ ]. A célula combustível tem como produto a geração de corrente elétrica em modo contínuo, 
desde que o combustível e o oxigênio sejam fornecidos. A operação em regime contínuo produz uma corrente elétrica contínua estacionária. Na célula combustível, a potência química é obtida em função da variação do potencial químico ( $\left.\mu_{\text {produto }}-\mu_{\text {reagente }}\right)$ e da velocidade de reação química $\left(J^{\prime \prime}\right)$ e a potencia elétrica $(P)$ é uma função da variação do potencial ou voltagem $\left(\varphi_{2}-\varphi_{1}\right)$ e da corrente elétrica $(I)$ [9]].

Por analogia com a célula combustível, pode-se inferir que a potência química para "dye-cells" também pode ser interpretada como sendo função da variação do potencial químico e velocidade da reação $(J)$. De forma que o produto é a molécula de corante no estado excitado $\left(A^{*}\right)$ com potencial químico associado $\mu_{A^{*}}$ e o reagente é a molécula de corante no estado fundamental $(A)$ com potencial químico associado $\mu_{A}$.

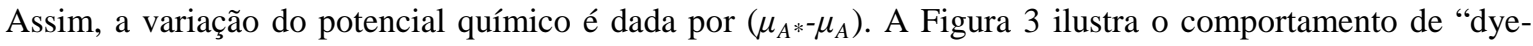
cells”, em analogia a uma célula combustível.

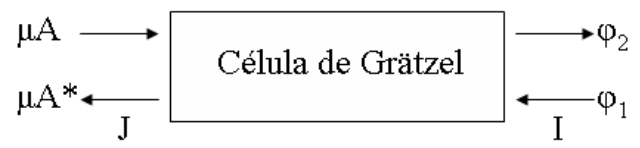

Figura 3: Esquema de funcionamento de células fotossensibilizadas com corante (Celula de Grätzel) relacionando à potência química (lado esquerdo) com a potência elétrica (lado direito).

Ao considerar que para a célula fotossensibilizada ou "dye-cell” a potência elétrica $(P)$ é obtida da mesma maneira que para a célula combustível, isto é, em função da diferença entre os potenciais elétricos $\left(\varphi_{2}-\varphi_{1}\right)$ e da corrente elétrica $(I)$, então,

$$
P=\left(\varphi_{2}-\varphi_{1}\right) \cdot I
$$

A potência química $\left(P_{q}\right)$ para as células fotossensibilizadas, em analogia a potência química para a célula combustível, é obtida em função da diferença entre os potenciais químicos da molécula de corante nos dois estados possíveis durante o processo de operação da célula, $\left(\mu_{A^{*}}-\mu_{A}\right)$, e da velocidade da reação $(J)$, ou seja;

$$
P_{q}=\left(\mu_{A^{*}}-\mu_{A}\right) \cdot J
$$

O valor da velocidade da reação $(J)$ pode ser obtido com o auxílio da cinética química que permite deduzir a chamada equação da velocidade e por meio dessa equação é possível estimar a velocidade da reação química. Para a célula combustível, a velocidade da reação $\left(J^{\prime \prime}\right)$ e a corrente elétrica $(I)$ podem ser obtidas com o auxílio do parâmetro $z$ e da constante de Faraday $(F)$. O parâmetro $z$ é tanto uma função do potencial elétrico quanto do potencial químico [9] e as relações são representadas pelas Eq. (12a) e (12b). Ao reinterpretar as E Eqs. (12a) e (12b) para a célula fotossensibilizada, tem-se que $J^{\prime \prime}$ passa a ser $J$ e ( $\mu$ produto $-\mu$ reagente) passa a $\operatorname{ser}\left(\mu_{A^{*}-\mu_{A}}\right)$.

$$
\begin{aligned}
& \mathrm{J}^{\prime \prime}=\frac{I}{z \cdot F} \\
& Z=\frac{\left(\mu_{\text {produto }}-\mu_{\text {reagente }}\right)}{F \cdot\left(\varphi_{2}-\varphi_{1}\right)}
\end{aligned}
$$

Assim, a Eq. (12a) e a Eq. (12b) quando aplicadas às células fotossensibilizadas permitem estimar a velocidade da reação $(J)$. Para as células fotossensibilizadas, o retorno do corante do estado excitado ao estado fundamental implica a injeção de elétrons no semicondutor e, por conseguinte, a geração de corrente elétrica. Então, um rearranjo na Eq. (9a) permite estimar a variação do potencial químico $\left(\mu_{A^{*}}-\mu_{A}\right)$ em função dos parâmetros solares comprimento onda $(\lambda)$, ângulo sólido $(\Omega)$, temperatura da fonte de radiação $\left(T_{R}\right)$ e outros parâmetros. A potência química é igual à potência elétrica [9]. Pela Eq. 11 é possível estimar a potência química para uma fonte de radiação monocromática.

A maior voltagem que uma célula fotovoltaica pode atingir é a voltagem de circuito aberto $\left(V_{c a}\right)$ e a maior corrente elétrica é a corrente de curto-circuito (Icc) [1,2]. Tanto os valores de $V_{c a}$ quanto de $I_{c c}$ podem ser obtidos ou através de dados experimentais ou através de modelos baseados em circuitos elétricos. Assim, ao considerar a máxima voltagem e a máxima corrente, tanto a corrente quanto o potencial elétrico mostrados nas Eq. (12a) e Eq. (12b) podem ser interpretadas como sendo $I_{c c}$ e $V_{c a}$.

Para os valores de $V_{c a}$ e $I_{c c}$ obtidos sob a condição de radiação policromática, a velocidade da reação 
estimada pela Eq. (12a) deve adequar-se a mesma. Contudo, como mencionado anteriormente a variação do potencial químico é função da radiação monocromática. Assim, com o auxílio das Eqs. (9a) e (9c), a Eq. (11) pode ser reescrita de forma a representar a potência química gerada com a utilização de uma fonte de radiação policromática, representado por:

$$
P_{\theta}=\left(\mu_{A^{*}}-\mu_{A}\right) \cdot J \cdot \theta=\left(\mu_{A^{*}}-\mu_{A}\right) \cdot J_{\theta}
$$

Sendo que a variável $J_{\theta}$ é a chamada velocidade da reação quando na superfície estiver incidindo radiação policromática e $P_{\theta}$ a potência associada.

\section{RESULTADOS}

\subsection{Potência elétrica em célula fotossensibilizada com corante natural}

As células solares feitas a partir de silício são largamente empregadas na fabricação de módulos fotovoltaicos para gerar potência elétrica [12]. No entanto, células fotossensibilizadas com corantes (células de Grätzel) que utilizam corantes naturais ou artificiais fotossensíveis podem também gerar potência elétrica. No caso das células fotossensibilizadas, os valores dos principais parâmetros elétricos $\left(V_{c a}, I_{c c}\right.$, fator de forma e eficiência elétrica da célula) associados a cada corante permitem estimar a potência elétrica da célula sob radiação policromática artificial com AM 1,5 $[\underline{10}, \underline{11}]$. Assim, o entendimento de como ocorre o comportamento elétrico das células solares, a partir de dados experimentais ou uso de modelos matemáticos, torna-se importante para avaliar o desempenho das mesmas.

Neste trabalho, o modelo apresentado visa fornecer bases para o entendimento de fatores que afetam a eficiência de conversão da energia solar em eletricidade nas células de Grätzel. Uma vez que os valores $I_{c c} \mathrm{e}$ $V_{c a}$ são conhecidos, a velocidade da reação química $(J)$ pode ser estimada pelas Eqs. (12a) e (12b). A potência química pode ser estimada pela Eq. (13) que sob as hipóteses de estado estacionário, célula trabalhando a temperatura ambiente e processo reversível, implica na própria potência elétrica. A Tabela 1 contém os valores dos parâmetros e dimensões usados no modelo teórico que relaciona a potência elétrica com a potência química em células fotossensibilizadas com corante.

A Tabela 2 mostra os valores obtidos a partir do modelo teórico fundamentado neste trabalho, considerando o sol um corpo negro, e os dados da literatura para três corantes naturais a AM 1,5 [10]. Além disso, para gerar os valores pelo modelo, assume-se que para AM 1,5 a irradiância média $\left(I_{\lambda}\right)$ possui valor de 1,16 $\mathrm{W} \cdot \mathrm{m}^{-2} \cdot \mathrm{nm}^{-1}$ e $\Omega=6,8 \times 10^{-5}$. Observa-se que há diferença entre os valores das potências elétrica e química, mostrados na Tabela 2. Esta diferença é devido ao fato de que a velocidade da reação $(J)$ e a fração da luz absorvida para a fonte de radiação policromática $(\theta)$ foi estimada em função dos parâmetros elétricos $V_{c a}$ e $I_{c c}$.

De forma a adequar o modelo aos valores experimentais, isto é, torna-lo mais representativo; posteriormente uma equação química para estimar $J$ em função da concentração do corante com o auxílio da cinética química poderá ser determinada. Também, uma equação para estimar $\theta$ com auxílio da termodinâmica aplicada à radiação poderá ser formulada posteriormente. De fato, tendo-se $J$ e $\theta$ independentes dos parâmetros elétricos $\left(V_{c a}\right.$ e $\left.I_{c c}\right)$ uma maior flexibilidade poderá ser conferida ao modelo para avaliação via sistema reacional das reações fotoquímicas em uma célula de Grätzel.

Tabela 1: Tabela de constantes e fatores de conversão.

\begin{tabular}{c|c|c|c}
\hline CONSTANTE & SÍMBOLO & VALOR & UNIDADE \\
\hline Velocidade da luz & $c$ & $2,997925 \times 10^{8}$ & $\mathrm{~m} . \mathrm{s}^{-1}$ \\
\hline Número de Avogadro & $N$ & $6,022045 \times 10^{23}$ & $\mathrm{~mol}^{-1}$ \\
\hline Constante de Planck & $h$ & $6,626176 \times 10^{-34}$ & $\mathrm{~J} . \mathrm{s}$ \\
\hline Constante dos gases & $R$ & $8,314126 \times 10^{0}$ & $\mathrm{~J} \cdot \mathrm{mol}^{-1} \cdot \mathrm{K}^{-1}$ \\
\hline Constante de Boltzmann & $k_{B}$ & $1,380662 \times 10^{-23}$ & $\mathrm{~J} . \mathrm{K}^{-1}$ \\
\hline Eletrón-volt & $e V$ & $1,6602189 \times 10^{-19}$ & $\mathrm{~J}$ \\
\hline Constante de Faraday & $F$ & $9,56 \times 10^{4}$ & $\mathrm{C} \cdot \mathrm{mol}^{-1}$ \\
\hline
\end{tabular}


LIMA, F.M., BEZERRA, K.P., MARQUES, M.K.D, MAIA JÚNIOR, P.H.F, FREIRE,F.N.A.,ALMEIDA,A.F.L. revista Matéria, v.20, n.2, pp. $344-352,2015$.

Tabela 2: Valores das potências elétrica e química.

\begin{tabular}{|c|c|c|c|c|c|c|c|c|}
\hline \multirow[b]{2}{*}{ Extrato } & \multirow[b]{2}{*}{$\begin{array}{c}\lambda \\
(\mathrm{nm})\end{array}$} & \multicolumn{4}{|c|}{ Dados da Literatura [10] } & \multicolumn{3}{|c|}{ Modelo } \\
\hline & & $\begin{array}{c}I_{c c} \\
\left(\mathrm{~mA} \cdot \mathrm{cm}^{-2}\right)\end{array}$ & $\begin{array}{l}V_{c a} \\
(\mathrm{~V})\end{array}$ & $\begin{array}{l}F F \\
(\%)\end{array}$ & $\begin{array}{c}P \\
\left(\mathrm{~mW} \cdot \mathrm{cm}^{-2}\right)\end{array}$ & $\begin{array}{c}\mu_{A^{*}-} \mu_{A} \\
\left(\mathrm{~J} \mathrm{~mol}^{-1}\right) \\
\end{array}$ & $\begin{array}{c}J_{\theta} \\
\left(\mathrm{mmol} \cdot \mathrm{s}^{-1} \cdot \mathrm{cm}^{-2}\right)\end{array}$ & $\begin{array}{c}P_{\theta} \\
\left(\mathrm{mW} \cdot \mathrm{cm}^{-2}\right)\end{array}$ \\
\hline $\begin{array}{c}\text { China } \\
\text { loropetala }\end{array}$ & 665 & 0,84 & 0,518 & 62,6 & 0,27 & $1,297 \times 10^{5}$ & $3,355 \times 10^{-6}$ & 0,44 \\
\hline Perilla & 665 & 1,36 & 0,522 & 69,6 & 0,50 & $1,297 \times 10^{5}$ & $5,474 \times 10^{-6}$ & 0,71 \\
\hline $\begin{array}{c}\text { Herba } \\
\text { artemisiae } \\
\text { Scopariaea }\end{array}$ & 669 & 1,03 & 0,484 & 68,5 & 0,34 & $1,261 \times 10^{5}$ & $3,952 \times 10^{-6}$ & 0,50 \\
\hline
\end{tabular}

\section{CONCLUSÕES}

O benefício resultante do desenvolvimento do modelo é o entendimento obtido sobre os fatores que influenciam o sistema físico sem a necessidade de ter que construir uma célula fotossensibilizada com corante. $\mathrm{O}$ posterior aperfeiçoamento do modelo a partir da análise de outros parâmetros, por exemplo, espessura da camada de corante e demais componentes das células permitirá melhorar o funcionamento de tais células. De forma que, conseguindo-se um modelo representativo o aperfeiçoamento do modelo implicará também na melhoria da eficiência das células fotossensibilizadas com corante.

O estudo dos fatores que influenciam a eficiência de conversão de energia solar nessas células, auxiliados por um modelo representativo permite o desenvolvimento de células fotovoltaicas orgânicas (células fotossensibilizadas com corante) mais eficientes e de menor custo para aplicação em escala industrial. A vantagem do uso de um modelo representativo é a possibilidade de testar diversas condições tanto do sistema físico quanto das condições ambientais durante o processo de conversão de energia solar em potência elétrica. Além disso, o entendimento do mecanismo envolvido poderá contribuir para melhorias de protótipos e diminuir inclusive os custos para construção de novos modelos experimentais.

\section{AGRADECIMENTOS}

Os autores agradecem a CAPES, ao CNPq e a FUNCAP.

\section{BIBLIOGRAFIA}

[1] QUASCHNING, V., Understanding Renewable Energy Systems, 1 ed., London, Earthscan, 2007.

[2] DUFFIE,J. A., BECKMAN,W. A., Solar Engineering of Thermal Processes, 3 ed., New Jersey, John Wiley \& Sons, Inc., 2006.

[3] HAGELDT,A., BOSCHLOO, G., SUN, L., et al., "Dye-Sensitized Solar Cells”, Chemical Reviews, v. 110, n. 11, pp. 6595-6663, Nov. 2010.

[4] KAMAT, P.V., TVRDY, K., BAKER, D. R., et al., "Beyond photovoltaics: semiconductor nanoarchitectures for liquid-junction solar cells”, Chemical Reviews, v. 110, n.11, pp. 6664-6688, Nov. 2010.

[5] KRAŠOVEC, U.O., BERGINC, M., HOČEVAR, M., et al., "Unique $\mathrm{TiO}_{2}$ paste for high efficiency dyesensitized solar cells”, Solar Energy Materials \& Solar Cells, v. 93, n. 3, pp. 379-381, Mar. 2009.

[6] GRÄTZEl, M., “Dye-sensitized solar cells”, Journal of Photochemistry and Photobiology C: Photochemistry Reviews, v. 4, n. 2, pp. 145-153, Oct. 2003.

[7] GRÄTZEL. M., MOSER, J.E. “Solar Energy Conversion”, In: Electron Transfer in Chemistry, v. 5, electron transfer processes, Wiley-Vch, pp.589-644, 2001.

[8] SMITH, J.M., VAN NESS, H. C., ABBOTT, M. M., Introdução à Termodinâmica da Engenharia Química, 7 ed, Rio de Janeiro, LCT - Livros Técnicos e Científicos, 2007.

[9] JOB, G. and HERRMANN, F., “Chemical potential-a quantity in search of recognition”, European Journal of Physics, v.27, n. 2, pp. 353-371, Marc. 2006. 
LIMA, F.M., BEZERRA, K.P., MARQUES, M.K.D, MAIA JÚNIOR, P.H.F, FREIRE,F.N.A.,ALMEIDA,A.F.L. revista Matéria, v.20, n.2, pp. $344-352,2015$.

[10] ZHOU, H., WU, L., GAO, Y., MA, T., “Dye-sensitized solar cells using 20 natural dyes as sensitizers”, Journal of Photochemistry and Photobiology A: Chemistry, v. 219, n. 2, pp. 188-194, Apr. 2011.

[11] CHANGA, H., WUB, H.M., CHENC, T.L., HUANGD, K.D., JWOE, C.S., LOA, Y.J., “Dye-sensitized solar cell using natural dyes extracted from spinach and ipomoea”, Journal of Alloys and Compounds, v. 495, n. 2, pp. 606-610, Apr. 2010.

[12] BRUSCHI, D.L., MOEHLECKE, A., ZANESCO, I., COSTA, R.C., “Desenvolvimento de células solares em silício tipo n com emissor formado por Boro”, Revista Matéria, v. 16, n. 3, pp. 775 - 787, 2011. 